\title{
The Improved Function and Commercial Design of the Intelligent Fitting System
}

\author{
Jingjing Zheng ${ }^{1}$, Jinhua Ruan ${ }^{1} \&$ Shouzhong $\mathrm{Hu}^{1}$ \\ ${ }^{1}$ Fashion Design and Engineering, Shanghai University of Engineering Science, shanghai, China \\ Correspondence: Shouzhong Hu, Professor, College of fashion, Shanghai University of Engineering Science, China. \\ E-mail: hushzh@sues.edu.cn
}

Received: March 15, 2015

Accepted: March 31, 2015

Online Published: April 5, 2015

doi:10.5430/jbar.v4n1p16

URL: http://dx.doi.org/10.5430/jbar.v4n1p16

\begin{abstract}
The intelligent fitting system refers to artificial intelligence, artificial intelligence is a research and development used for simulation, extending and expanding the theory, method, technology and application of intelligent system. It is a new technology of science. Artificial intelligence is a branch of computer science. It attempts to understand the essence of intelligence, and can produce a new kind of response in the form of human intelligence which is similar to intelligent machines. Research in this field includes robot, speech recognition, image recognition, natural language processing and expert system, etc. This article will investigate, summarize, analyze and determine the demanding functions of the system. By improving the fitting system and making commercial design, we hope that all we do can play a certain role in the development of the fitting system in the future.
\end{abstract}

Keywords: Clothing; The intelligent fitting system, Functional requirements analysis, Commercial design

\section{Introduction}

With the rapid development of the garment industry, the competitions of apparel retailers are increasingly competitive, while the retail methods of improvement and innovation become powerful means to seize the consumer market.

With the advent and application of intelligent fitting system, domestic and aboard garment enterprises pay more attention to the dressing room and dressing mirror (ZENG Xianhui, 2010). The great significance to the development of modern retail clothing business is how to determine the required functions of the Intelligent Fitting System, improve the existing systems and make commercial design.

In this paper, we understand the required functions of the intelligent fitting system for consumers through an integrated research. We improve on the existing intelligent fitting system according to the requirements, in order to test consumer's attention degree for the intelligent fitting system, and infer intelligent fitting systems market prospects.

\section{Intelligent Fitting System}

Intelligent Fitting System by Full HD cameras capture live video in real time, combined with body-sensory detection device apparel 2D images or 3D models superimposed on the image of customers, to achieve the perfect blend of virtual and real customer stature clothing. Intelligent Fitting System Smart Dressing Mirror use of radio frequency identification (RFID), as long as the customer before the clothes come handheld mirror, the mirror will immediately sense the clothes, and the side of the screen shows suggestions and mix material types, color and price, with its secret lies in a small bar code induction clothes (LI Yanmei, XU Mengtian, 2013). It mainly consists of two parts: First, by the projection of pre-stored slide and sizes reflect the fashion system; the second is the internal set up a mirror and dressing room with a control keyboard.

Intelligent Fitting System features (GAO Yupeng, LI Shiguo, 2010): 1) Fast and easy: the customer through the touch screen to operate, not only the details and the location of the clothing where rapid understanding of clothing; 2) Reduce purchase risk: customers through scenes and simulated body function, very intuitively watch their scenes dressed in the clothing of different effects, so as to avoid impulse shopping; 3) Extend the shelf: allowing consumers to learn more about commodities and richer choice; 4) Increase the participation of the customer: customers can not only choose the appropriate mix, you can also interact with friends and family via video transmission and improve 
the shopping enthusiasm of customer.

\section{The needs of The Intelligent Fitting System}

\subsection{The research design of the function of The Intelligent Fitting System}

This study used questionnaires as the primary method to collect the information required for the study, supplemented by interviews, data analysis used to verify comprehension questions arise. The main project for the Shanghai Institute of Clothing Technology University teachers and students as well as addition of online shopping more school students to conduct research, primarily in terms of staff the intelligent fitting system personnel understand and online shopping more staff to conduct research; There are retirees research (CHEN Nuo, 2013). By from students, staff, retirees and other researchers from different angles, data processing functions of different consumer groups summed up demand for the intelligent fitting system.

Questionnaire in this study consists of four main sections: Introduction, consumers' background, Suitable of intelligent fitting systems for consumers and the understanding of consumers for the functional requirements. The questionnaire set up 12 topics.

From 2014 January 3 to January 17 in Shanghai, corporate employees, freelancers and retirees answered the questionnaire. The survey questionnaires were distributed and 500 copies for the consumer to recover 443 copies, of which 415 valid questionnaires, the recovery rate was $88.6 \%$.

\subsection{The intelligent fitting system functional requirements analysis}

\subsubsection{Consumer inconvenience fitting process, problems and suggestions for fitting areas}

As can be seen from Table 3-1,65\% of people think that is too much trouble finding clothes that fit in the process of fitting a lot of inconvenience, 72 percent of people think that change of clothes is too much trouble.

Table 1. Statistics of the problems existed in the fitting room at present

\begin{tabular}{|c|c|c|c|c|}
\hline \multirow{4}{*}{ Inconvenience } & & \multicolumn{2}{|c|}{ Response } & \multirow{2}{*}{$\begin{array}{c}\text { Case } \\
\text { percentage }\end{array}$} \\
\hline & & $\mathrm{N}$ & percentage & \\
\hline & Difficult in finding proper clothing & 269 & $27.60 \%$ & $65.00 \%$ \\
\hline & Troublesome in Change clothes & 298 & $30.60 \%$ & $72.00 \%$ \\
\hline \multirow[t]{3}{*}{ In the fitting process } & $\begin{array}{c}\text { The body' privacy is leaked } \\
\text { Protection }\end{array}$ & 188 & $19.30 \%$ & $45.40 \%$ \\
\hline & Destruction of make up look & 142 & $14.60 \%$ & $34.30 \%$ \\
\hline & others & 77 & $7.90 \%$ & $18.60 \%$ \\
\hline \multicolumn{2}{|c|}{ total } & 974 & $100.00 \%$ & $235.30 \%$ \\
\hline \multirow{5}{*}{$\begin{array}{l}\text { The problems in the fitting process } \\
\text { reduce your purchase enthusiasm of } \\
\text { clothing }\end{array}$} & The release of privacy, unsafe & 218 & $20.50 \%$ & $52.50 \%$ \\
\hline & Lack of necessary equipment & 216 & $20.30 \%$ & $52.00 \%$ \\
\hline & The fitting room small or random & 274 & $25.80 \%$ & $66.00 \%$ \\
\hline & Unable to quickly find tight clothes & 283 & $26.60 \%$ & $68.20 \%$ \\
\hline & ers & 71 & $6.70 \%$ & $17.10 \%$ \\
\hline To & & 1062 & $100.00 \%$ & $255.90 \%$ \\
\hline What kind of & Necessary equipment complete & 294 & $33.00 \%$ & $71.40 \%$ \\
\hline Services should & Privacy is protected & 203 & $22.80 \%$ & $49.30 \%$ \\
\hline \multirow[t]{3}{*}{$\begin{array}{c}\text { Shopping malls and clothing store } \\
\text { services in terms of the fitting in } \\
\text { your point }\end{array}$} & Customer self-service fitting & 322 & $36.10 \%$ & $78.20 \%$ \\
\hline & Others & 72 & $8.10 \%$ & $17.50 \%$ \\
\hline & Total & 891 & $100.00 \%$ & $216.30 \%$ \\
\hline
\end{tabular}

\subsubsection{Consumers understand the extent and the degree of concern for the Smart Dressing}

Figure 3-1 shows there are 44 samples in the sample contact or to find out about intelligent fitting system, the proportion was $10.6 \%, 371$ samples have no contact with intelligent fitting system, the proportion was $89.4 \%$. So the low popularity of the intelligent fitting system, the application rate is poor. The degree of concern for the smart 
consumer fitting system, there are 399 samples considered if there is intelligent clothing store or mall fitting system, it will cause the attention of consumers, their proportion of the number of samples was $96.1 \%$, but 16 samples think not a cause for concern, accounting for $3.9 \%$ of samples. This problem description the intelligent fitting systems market is large, consumers are interested in the system.

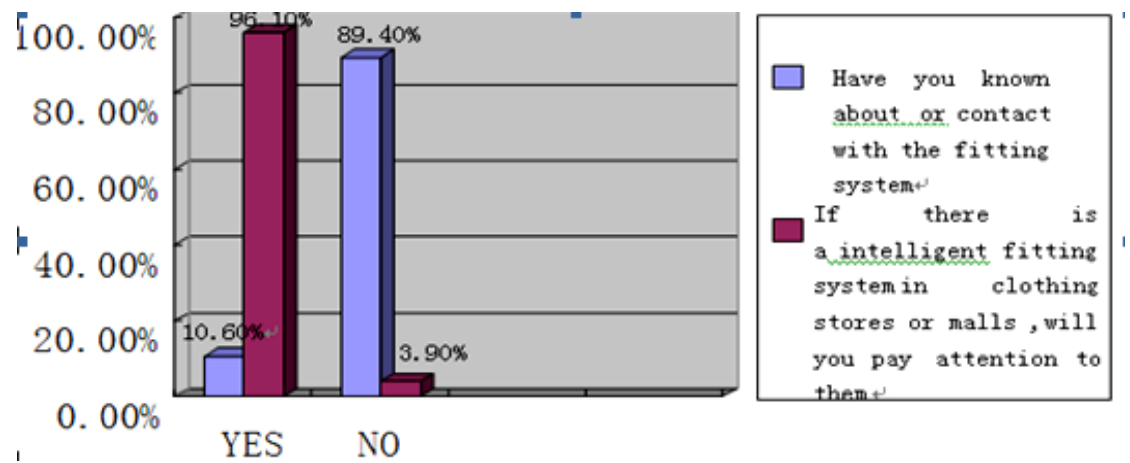

Figure 1. Consumers' understanding and concern to intelligence of the fitting

3.2.3 Consumers basic situation and the problem of fitting and fitting systems for intelligent correlation between the concern degree

Table 2 shows the correlation, occupation, age, gender, whether before contact with intelligent fitting systems and fitting system will cause the correlation between your attention, which are not person correlation coefficient close to 1 or -1 but its significance $>0.05$, this phenomenon shows no correlation between these five factors sex, no matter what the age, occupation and gender on whether contact with intelligent fitting system five correlations, indicating a very low penetration of the intelligent fitting system application of the poor. But no matter what the age, occupation and gender are concerned about the intelligent fitting system, indicating that consumers' demand for the intelligent fitting system for many, no matter what the person for the intelligent fitting system has warm, intelligent dressing system description great market prospects.

Table 2. The correlation between Basic information of consumer and their attention to the system

\begin{tabular}{|c|c|c|c|c|c|c|}
\hline \multirow{3}{*}{ profession } & \multirow{3}{*}{$\begin{array}{c}\text { Pearson correlation } \\
\text { significance(two sides) }\end{array}$} & profession & $\begin{array}{l}\text { If contact with the } \\
\text { fitting system }\end{array}$ & $\begin{array}{l}\text { If The fitting } \\
\text { system can cause } \\
\text { your attention }\end{array}$ & gender & age \\
\hline & & 1 & .027 & .076 & $-.120 *$ & $.269 * *$ \\
\hline & & & .582 & .123 & .014 & .000 \\
\hline \multirow{2}{*}{$\begin{array}{l}\text { If contact with } \\
\text { the fitting } \\
\text { system }\end{array}$} & \multirow{2}{*}{$\begin{array}{c}\text { Pearson correlation } \\
\text { significance(two sides) }\end{array}$} & .027 & 1 & -.012 & -.016 & .083 \\
\hline & & .582 & & .802 & .752 & .092 \\
\hline \multirow{4}{*}{$\begin{array}{l}\text { If The fitting } \\
\text { system can } \\
\text { cause your } \\
\text { attention } \\
\text { gender }\end{array}$} & \multirow{2}{*}{$\begin{array}{c}\text { Pearson correlation } \\
\text { significance(two sides) }\end{array}$} & .076 & -.012 & \multirow[t]{2}{*}{1} & .016 & -.022 \\
\hline & & .123 & .802 & & .747 & .651 \\
\hline & Pearson correlation & $-.120 *$ & -.016 & .016 & 1 & -.007 \\
\hline & significance(two sides) & .014 & .752 & .747 & & .886 \\
\hline age & Pearson correlation & $.269^{* *}$ & .083 & -.022 & -.007 & 1 \\
\hline & significance(two sides) & .000 & .092 & .651 & .886 & \\
\hline & $\mathrm{N}$ & 415 & 415 & 415 & 415 & 415 \\
\hline
\end{tabular}

Table 3 and Table 4 and Table 5 and can be seen inconvenience occupation, age, gender and fitting process will occur no correlation with the fitting process, which will reduce the problem buying enthusiasm has not correlated with the fitting process for service no significant correlation. No matter what kind of job description, roughly the same age and gender perspectives fitting for any inconvenience, and it can be seen that we have to try to solve these inconveniences of the functional design of the system. 
Table 3. Consumers' basic situation and problems in the process of the fitting correlation

\begin{tabular}{|c|c|c|c|c|c|c|}
\hline & & $\begin{array}{l}\text { Looking forC } \\
\text { tight clothes } \\
\text { more } \\
\text { troublesome }\end{array}$ & $\begin{array}{l}\text { hanging clothes } \\
\text { more } \\
\text { troublesome }\end{array}$ & $\begin{array}{l}\text { Privacy, not } \\
\text { security }\end{array}$ & $\begin{array}{c}\text { The problems of } \\
\text { makeup }\end{array}$ & else \\
\hline \multirow[t]{3}{*}{ profession } & Pearson correlation & $.126^{* *}$ & .024 & $.125^{*}$ & .047 & .058 \\
\hline & significance(two sides) & .010 & .621 & .011 & .344 & .236 \\
\hline & $\mathrm{N}$ & 415 & 415 & 415 & 415 & 415 \\
\hline \multirow[t]{3}{*}{ gender } & Pearson correlation & -.077 & .001 & $.113^{*}$ & .018 & -.003 \\
\hline & significance(two sides) & .116 & .977 & .021 & .718 & .947 \\
\hline & $\mathrm{N}$ & 415 & 415 & 415 & 415 & 415 \\
\hline \multirow[t]{3}{*}{ age } & Pearson correlation & .052 & .079 & $.103 *$ & -.031 & .004 \\
\hline & significance(two sides) & .286 & .109 & .036 & .531 & .936 \\
\hline & $\mathrm{N}$ & 415 & 415 & 415 & 415 & 415 \\
\hline
\end{tabular}

Table 4. Consumers' basic situation and the fitting room is what problems will reduce the correlation of clothing purchase enthusiasm

\begin{tabular}{|c|c|c|c|c|c|c|}
\hline \multirow{4}{*}{ profession } & & $\begin{array}{l}\text { The fitting } \\
\text { room small } \\
\text { or random }\end{array}$ & $\begin{array}{c}\text { Privacy, not } \\
\text { security }\end{array}$ & $\begin{array}{c}\text { Lack of } \\
\text { necessary } \\
\text { equipment }\end{array}$ & $\begin{array}{l}\text { Unable to } \\
\text { quickly find } \\
\text { tight clothes }\end{array}$ & else \\
\hline & & .027 & .040 & $.166^{* *}$ & .079 & .062 \\
\hline & significance(two sides) & .577 & .421 & .001 & .110 & .208 \\
\hline & $\mathrm{N}$ & 415 & 415 & 415 & 415 & 415 \\
\hline \multirow[t]{3}{*}{ gender } & Pearson correlation & .038 & $.106^{*}$ & .049 & .021 & -.078 \\
\hline & significance(two sides) & .440 & .030 & .321 & .671 & .110 \\
\hline & $\mathrm{N}$ & 415 & 415 & 415 & 415 & 415 \\
\hline \multirow[t]{4}{*}{ age } & Pearson correlation & .027 & .030 & $.129 * *$ & .096 & -.019 \\
\hline & significance(two sides) & .585 & .548 & .008 & .050 & .693 \\
\hline & $\mathrm{N}$ & 415 & 415 & 415 & 415 & 415 \\
\hline & $\mathrm{N}$ & 415 & 415 & 415 & 415 & 415 \\
\hline
\end{tabular}

Table 5. Consumers' basic situation and correlation of the fitting should provide what services

\begin{tabular}{|c|c|c|c|c|c|}
\hline & & $\begin{array}{c}\text { Customer self-service } \\
\text { the fitting }\end{array}$ & $\begin{array}{l}\text { Necessary } \\
\text { equipment } \\
\text { complete }\end{array}$ & $\begin{array}{l}\text { Privacy is } \\
\text { protected }\end{array}$ & else \\
\hline \multirow[t]{3}{*}{ profession } & Pearson correlation & -.013 & .096 & -.070 & -.025 \\
\hline & significance(two sides) & .791 & .051 & .155 & .608 \\
\hline & $\mathrm{N}$ & 415 & 415 & 415 & 415 \\
\hline \multirow[t]{3}{*}{ gender } & Pearson correlation & .065 & -.050 & .037 & -.021 \\
\hline & significance(two sides) & .185 & .308 & .450 & .670 \\
\hline & $\mathrm{N}$ & 415 & 415 & 415 & 415 \\
\hline \multirow[t]{3}{*}{ age } & Pearson correlation & .000 & $.123 *$ & -.029 & -.024 \\
\hline & significance(two sides) & .995 & .013 & .554 & .622 \\
\hline & $\mathrm{N}$ & 415 & 415 & 415 & 415 \\
\hline
\end{tabular}

\section{Improvements of the Intelligent Fitting System}

\subsection{Scale reliability and validity analysis}

In this study, a total of two scales, one is contacting consumers before describing smart dressing or learning how well the system functions, a total of five questions of measurement; the other is to describe the function of self-importance buying clothes, a total of 10 questions measuring items. In this paper, Cronbach's $\alpha$ reliability estimation methods to estimate the reliability of the questionnaire.

Cronbach's

Here, $\mathrm{k}$ is the number of questions, the questionnaire variance for each question.

As shown in Table 6 and Table 7 for the first scale and the second scale "if the item has been removed is to measure," 
said the output of a proposed basic statistics to assess the project after every convenience an assessment of the project individually assessed and reliability analysis of two scales shown in Table 8 and Table 9, the overall scale of a total value of 0.981 Cronbach's Alpha, Scale II Cronbach's Alpha value is 0.710 . Cronbach's Alpha value in the range of 0.65 to 0.70 is acceptable values, in the range of 0.70 to 0.80 . The value between 0.80 and 0.90 is very good. So Cronbach these two scales are more ideal, and each index entry has been deleted Cronbach's Alpha value is not significantly increased, so keep all indicators.

Table 6. The first scale: general statistics of the subjects

\begin{tabular}{|lcccc|}
\hline $\begin{array}{l}\text { Know or contact intelligent the } \\
\text { fitting degree of system function is } \\
\text { good or bad }\end{array}$ & $\begin{array}{c}\text { The average } \\
\text { scale has been } \\
\text { deleted }\end{array}$ & $\begin{array}{c}\text { A deleted } \\
\text { scale variance }\end{array}$ & $\begin{array}{c}\text { Correction of a } \\
\text { total correlation } \\
\text { function }\end{array}$ & $\begin{array}{c}\text { A deleted } \\
\text { Cronbach's } \\
\text { Alpha value }\end{array}$ \\
Convenient operation function & 1.4699 & 17.370 & .954 & .976 \\
Collocation instruction function & 1.4193 & 16.186 & .961 & .972 \\
Visual experience function & 1.4434 & 16.900 & .951 & .974 \\
Information consumption and the & 1.3976 & 15.902 & .931 & .980 \\
Shared function & & & & \\
\end{tabular}

Table 7. the second scale: general statistics of the subjects

\begin{tabular}{|c|c|c|c|c|}
\hline importance of Self-service shop function & $\begin{array}{c}\text { The average } \\
\text { scale has } \\
\text { been deleted }\end{array}$ & $\begin{array}{c}\text { A deleted } \\
\text { scale variance }\end{array}$ & $\begin{array}{l}\text { Correction of } \\
\text { total correlation }\end{array}$ & $\begin{array}{l}\text { A deleted Cronbach } \\
\text { 's Alpha value }\end{array}$ \\
\hline Can simulate real(action, figure, situation) & 30.6540 & 31.577 & .187 & .715 \\
\hline $\begin{array}{l}\text { Different wearing results in multi-angle } \\
\text { observation }\end{array}$ & 30.6254 & 28.210 & .497 & .667 \\
\hline show the details of clothes(quality, location) & 31.2222 & 26.753 & .482 & .666 \\
\hline Proposed amendments to the clothing & 31.8508 & 26.726 & .439 & .674 \\
\hline $\begin{array}{l}\text { Can preview clothing pictures and wearing } \\
\text { effect in models }\end{array}$ & 30.9048 & 27.857 & .472 & .669 \\
\hline $\begin{array}{l}\text { Show the clothing sales, and the evaluation } \\
\text { of the customer }\end{array}$ & 30.3619 & 30.939 & .236 & .708 \\
\hline $\begin{array}{l}\text { Can interact with family and friends, and } \\
\text { other customers }\end{array}$ & 30.9968 & 30.908 & .237 & .708 \\
\hline $\begin{array}{l}\text { Can save the database information(height, } \\
\text { measurements) }\end{array}$ & 31.7492 & 27.182 & .453 & .671 \\
\hline Show the tend and suggestions & 30.7111 & 30.620 & .282 & .701 \\
\hline Show clothing collocation & 30.4095 & 30.032 & .392 & .685 \\
\hline
\end{tabular}

\subsection{Factor Analysis}

In this study, we use construct validity to analyze consumer demand for functional the intelligent fitting system. The factor analysis is the main measurement methods of construct validity. The original variables are divided into several categories initial, high correlation into a class (TAN Huang, 2009), low correlation into a class. Eventually we can use a few common factors to represent all variables. Research by spss20 software Scale exploratory factor analysis, using principal component analysis to factor extraction and Maximum variance or orthogonality rotation combination, the standard of factors extraction is that the eigenvingue is bigger than 1. Before going to use factor analysis KMO test to test, the scale is appropriate for factor analysis. When KMO value close to 1, it shows suitable 
for factor analysis.

1) It can be seen in Table 8 Kaiser-Meyer-01kin value of 0.680 , is closer to 1 , indicating suitable for factor analysis

Table 8. The check of 4-6KMO and Bartlett

$\begin{array}{ll}\text { Take out the enough Kaiser-Meyer-Olkin metrics } \\ & \text { The approximate } \\ & \text { chi-square } \\ \text { Bartlett Sphericity test } & \text { df } \\ & \text { Sig. }\end{array}$

.680

603.636

45

.000

Table 9. The total variance of the functional requirements explanation

\begin{tabular}{|c|c|c|c|c|c|c|c|c|c|}
\hline \multirow[t]{2}{*}{$\begin{array}{l}\text { Ingred } \\
\text { ients }\end{array}$} & \multicolumn{3}{|c|}{ The initial eigenvalue } & \multicolumn{3}{|c|}{$\begin{array}{c}\text { Extraction of sum of squares } \\
\text { loaded }\end{array}$} & \multicolumn{3}{|c|}{ Rotate the sum of squares loaded } \\
\hline & sum & $\begin{array}{c}\text { The } \\
\text { variance } \%\end{array}$ & $\begin{array}{c}\text { The } \\
\text { cumulative } \\
\%\end{array}$ & sum & $\begin{array}{c}\text { The } \\
\text { variance } \%\end{array}$ & $\begin{array}{c}\text { The } \\
\text { cumulative } \\
\%\end{array}$ & sum & $\begin{array}{c}\text { The } \\
\text { variance } \\
\%\end{array}$ & $\begin{array}{c}\text { The } \\
\text { cumulative } \\
\%\end{array}$ \\
\hline 1 & 2.451 & 24.512 & 24.512 & 2.451 & 24.512 & 24.512 & 2.238 & 22.379 & 22.379 \\
\hline 2 & 1.678 & 16.783 & 41.295 & 1.678 & 16.783 & 41.295 & 1.714 & 17.140 & 39.519 \\
\hline 3 & 1.253 & 12.531 & 53.826 & 1.253 & 12.531 & 53.826 & 1.431 & 14.308 & 53.826 \\
\hline 4 & .934 & 9.337 & 63.163 & & & & & & \\
\hline 5 & .774 & 7.745 & 70.908 & & & & & & \\
\hline 6 & .712 & 7.120 & 78.028 & & & & & & \\
\hline 7 & .670 & 6.702 & 84.730 & & & & & & \\
\hline 8 & .592 & 5.917 & 90.647 & & & & & & \\
\hline 9 & .497 & 4.973 & 95.620 & & & & & & \\
\hline 10 & .438 & 4.380 & 100.000 & & & & & & \\
\hline
\end{tabular}

Table 10. Rotation matrix of Ingredients

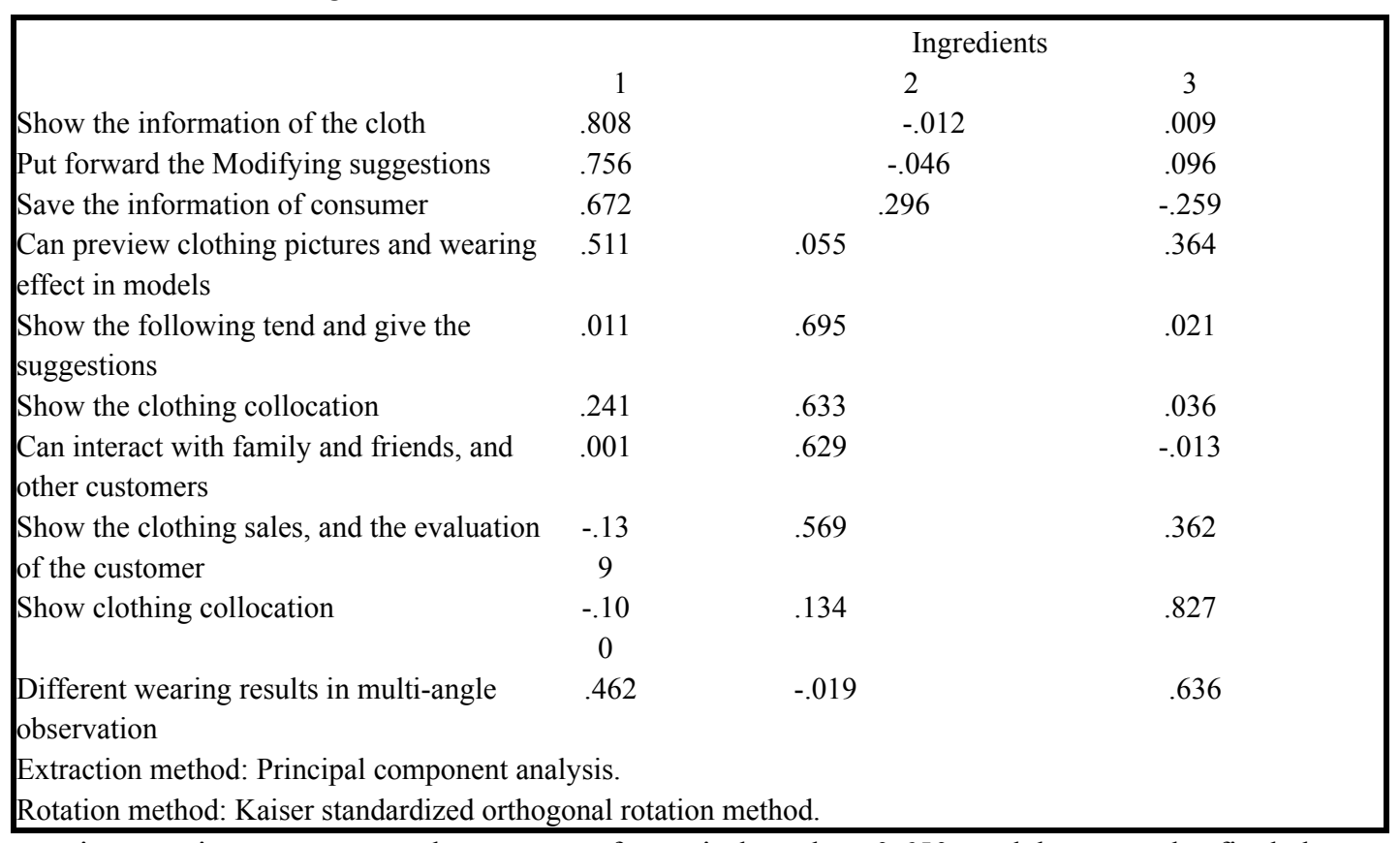

By the rotation matrix components, the common factor is less than 0.650 to delete, get the final three common factors, a common factor corresponding to the measured variable is the "Show details clothes", "may propose amendments to the clothing," and " Save the database information of customers ", because the first factor is the display module, but the latter two factors are background processing module, whose main operations are carried out by database management, this article will be named as" data management capabilities "; the common second factor 
is the "Show trends and suggest modifications", because this factor is to the customer and the designer to participate in the trend forecasting, this article will be named as "resource sharing function"; the common third factor is "simulated reality ".This paper will be named as" visual experience features. "

\section{Business system design of the Intelligent Fitting System}

As shown in Figure 2 shows, RIIT system customers use the process and Figure 3 shows, the process improved system used by customers. It can be drawn from the people on the basis of the original system ,improvement of needs are the following three points:1) Save the customer database information; 2)Suggest modifications of clothing and evaluation; 3)Simulate real wearing action scenes; 4)Show the location of clothing.

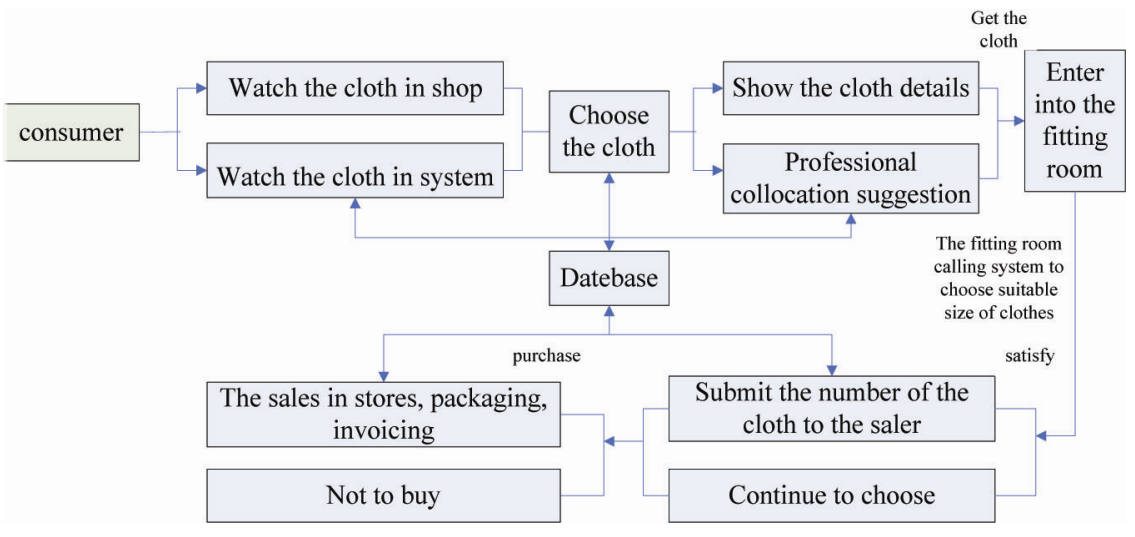

Figure 2. RIIT system customers use the process

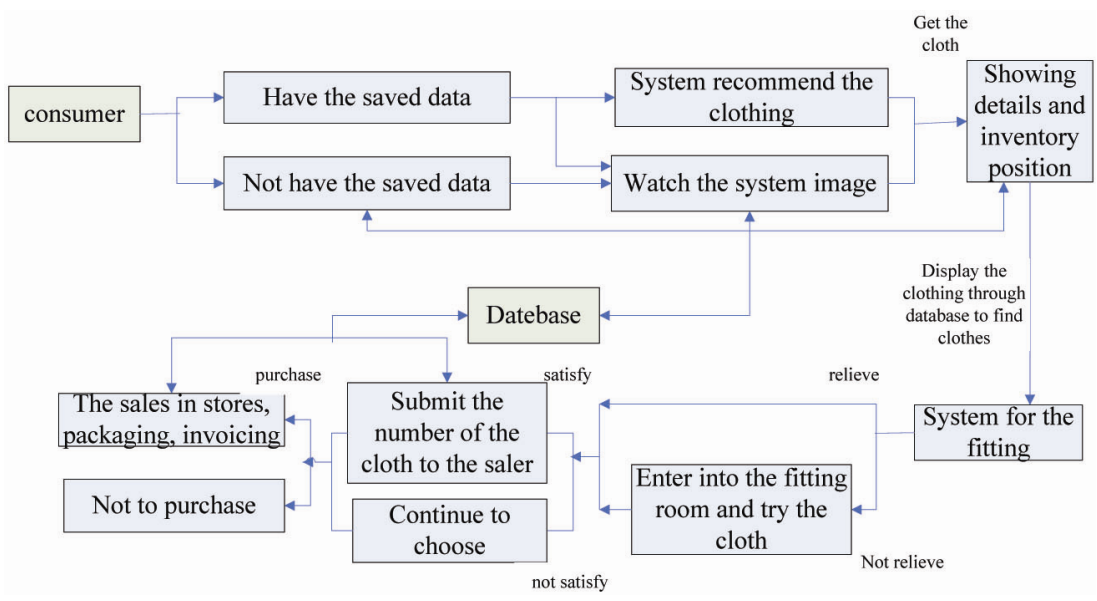

Figure 3. The process improved system used by customers

\section{The conclusion and prospect}

Objectively speaking, there are inevitable limitations of the system. There are many aspects that could be improved. The research has the following disadvantages:1) Analog dressing effect is not ideal: research in simulated real fitting in this regard, the lack of technology and software development in this area resulted in no-consistent with the imaginary virtual wearing effects, it is unable to meet our customers' temperament.2)The access to inaccurate sizes of customers: through the customer's own measure, the measurement errors are possible ,due to different people in different generated will, which leads to a fitting errors.3) The less of Enterprise Application: Due to constraints and funding, the system is unable to actually run in the enterprise, it can only be achieved through the application of theoretical guidance. The system is unable to provide an improved method for a variety of different types of clothing enterprises.

Take the actual needs of the fitting of simulation fidelity and apparel retail stores into consideration. Future research and further improvements for the system, the following areas:1)Improve timely fitting simulation: according to the person's temperament to simulate people.2) Be simulated clerk shopping scene: Although the intelligent fitting 
system can not only reduce the trouble fitting the customer, but also can reduce the amount of clothing store clerk and take stock of tedious.3)To achieve combination of online and offline services: according to customer needs ,to combine online and offline shopping.

There are many weakness in the paper: 1)the mount of the date is still limited, so the result can be more accurate.2)the method to improve the system is simple, another fine method will be found in the future.3)the time is so limited that the work in research is not completed well.

\section{Acknowledgements}

This project is sponsored by Shanghai University of Engineering Science 2015-year Innovation Fund for Graduate Students.

This study was funded by Science Technology Commission of Shanghai Municipality, the funded project No. 11510501600 and Municipal Education Commission of Shanghai , the funded project No. 13ZS128.

\section{References}

CHEN Nuo. (2013). Based Clothing Brand Experience Marketing Theory Dressing Room Setting Research. Zhejiang University of Technology.

GAO Yupeng, LI Shiguo. (2010). Psychology Based on User Demand "Consumer Experience" Analysis and Behavior. Packaging Engineering, 2010,20: 70-73.

HU Wanyue, LI Yanmei, Wang Yingmei, Wu Xiaonuo. (2014). Development Status and Prospect of Virtual Fitting. Shanghai University of Engineering Science, 2014,02: 162-165.

HUANG Zhenzhen, ZHANG Hongzhi. (2012). Clothing Retail Terminal Information Management System. Zhejiang Textile \& Fashion Vocational and Technical College, 2012,02: 72-76.

JIN Hongsheng. (2012). 3D Fitting Clothing Online Marketing System Research. Shandong Textile Economy, 2012,08: 48-51.

LI Yanmei, XU Mengtian. (2013). Smart Wardrobe - A New Concept in the Fashion Industry. fashion color, 2013,03: 112-113.

PENG Shengqiong. (2014). Comparative Study. Virtual Clothing Display System of Art and Design (theory), 2014,06: 71-73.

TAN Huang. (2009). Network Virtual Garment Fitting System Analysis and Design. Shandong University.

XIONG Yu. (2013). Research Collaborative Filtering Personalized Service E-commerce Recommendation System. University of Electronic Science and Technology, 2013.

ZENG Xianhui. (2010). Dress Smart Adapter System and Its Application. Donghua University. 